\title{
Effect of physical training on anxiety and self-esteem of obese adolescents.
}

\author{
Mohamed Ali Baccouche ${ }^{1}$, Ichraf Arous ${ }^{1}$, Khaled Trabelsi ${ }^{2}$, Liwa Masmoudi ${ }^{3}$, \\ Ali Elloumi ${ }^{4}$ \\ ${ }^{I}$ High Institute of Sport and Physical Education, University of Sfax, Tunisia. \\ ${ }^{2}$ Laboratory of Pharmacology, University of Medicine, Sfax, Tunisia. \\ ${ }^{3}$ Research Unit, High Institute of Sport and Physical Education, University of Sfax, Tunisia. \\ ${ }^{4}$ Labortory SYFACTE, Faculty of Letters and Humanities, University of Sfax, Tunisia.
}

\begin{abstract}
The decrease in physical activities plays an important role in the increased prevalence of obesity. Obese adolescents appear to experience greater dissatisfaction with their body image and be more likely to have psychological disorders. The aim of this study is to investigate the effect of a training program on anxiety and self-esteem among adolescents obese and non obese. Thus, two groups of children (obese and non obese) have followed a training program for 12 weeks. Levels of anxiety and self-esteem were evaluated before and after the training program by a questionnaire of self-esteem and state anxiety inventory. Our results showed that obese subjects are characterized by low self-esteem $(p<0.001)$ and high anxiety $(p<0.001)$ compared to non-obese subjects. However, after the training program, there is no significant difference between obese and non-obese for the self-esteem $(p=0.103)$, but for the anxiety, the obese are more anxious than the non-obese $(p$ $<0.001)$. Our results also showed an improvement in self-esteem $(+17.9 \% ; p<0.001)$ and decreased anxiety ($16.3 \% ; p<0.001)$ after the training program in obese subjects. Our study shows the importance of physical activities for obese adolescents in their identity development and emotional control. In addition, adequate nutrition associated with a moderate intensity sport is necessary for weight control.
\end{abstract}

Keywords: Adolescents, Anxiety, Obesity, Self-esteem.

\section{Introduction}

In recent decades, childhood obesity has increased steadily in industrialized countries [1]; [2] as well as in developing ones [3]. Overweight and obesity in childhood and adolescence is associated with an increased risk of adult obesity and its associated morbidities [4]; [5]. Adolescence is a critical time in the development of obesity [6]. The attendant metabolic changes and the decline in physical activity increase the likelihood of weight gain in this age group [7]; [8]; [9]. During childhood, and particularly in puberty, obesity is associated with lower levels of physical activity [10]. Physical activity is recommended as a key strategy in obesity prevention in young people [11]. Physical fitness, along with fatness, contributes to the metabolic health of adolescents [12].

Decreased physical activities and an unbalanced diet play a role in the increased prevalence of obesity [13]. Chronic lack of physical activity gradually alters the physical fitness among children and adolescents, who are overweight: cardio-respiratory limitation at effort, disturbed psychomotor development and increase in musculoskeletal disorders... [14] without forget the considerable social and psychological impact of obesity. In fact, overweight children are indeed more vulnerable to ridicule from their peers, they will develop attitudes of avoidance or rejection of sports [15]. These young people are therefore limited in their practical daily physical and leisure activities [16].

According to the World Health Organization (OMS, [17]), overweight and obesity is measured by the body mass index (BMI). Anyone with a BMI $\geq 25$ is considered overweight and a BMI $\geq 30$ is considered obese.

The obese child in full identity construction and in search of his/her own benchmarks, who feel rejected by his entourage, will have a low self-esteem. However, during adolescence, body image becomes a crucial choice in building self-esteem [18]; [19]. Similarly, obese adolescents seem to experience greater dissatisfaction with their body image and are more likely to have psychological disorders [20]. In this regard, physical activity appears therefore to be one of the best solutions to enable him/her to face his/her body, his abilities, and others, and allow it to exceed its estimated self-esteem. The child facing this reflected negative image a returned will be led to doubt his own abilities. This generates anxiety provoking questioning which prevents spontaneous participation. However, psychological factors such as anxiety and self-esteem are a major risk factor in the development of obesity [21]. Subjects with high levels of trait anxiety would also like to have a low self-esteem [22]; [23]; [24]. Self-esteem also appears to be a better predictor of trait anxiety perceived than the specific skill. 
Some authors reported negative correlations between self-esteem and depression [25]; [26] as well as anxiety [27]. However, early and severity of obesity in childhood and adolescence in all countries led to the development of extensive research on early detection, care, treatment and prevention of obesity for which physical activity appears to be a major factor.

Recent years have witnessed the proliferation of the number and type of fitness programs offered to sedentary adults for a loss to height and weight. This fact has necessitated the formulation of guidelines and training programs aimed at improving the quality of life of these individuals. However, the effect of a training program on anxiety and self-esteem in obese adolescents is not well known. In addition, to the best of our knowledge, no study has addressed the effects of a training program on anxiety and self-esteem in obese adolescents.

Therefore, the aim of this research is to study the effect of a training program on anxiety and selfesteem among obese and non obese adolescents.

\subsection{Subjects}

\section{Methods}

Twelve obese adolescents' boys aged from 14 to 17 years, enrolled in colleges and secondary schools in the public urban area of Mahdia, voluntarily participated in this study, whose body mass index (BMI) was greater than 97th percentile, as defined by French population curves [30]. In addition, a control group of nineteen adolescents with a BMI called normal have participated in this study.

None of the subjects were using drugs or other therapy for obesity, and none had prior histories of disease or injury that would prevent daily exercise.

Before enrolling in the study, subjects were informed of the experimental procedures, as well as the potential risks and benefits associated with the study; however, they were not informed of the study's purpose. To be included in the study, each subject provided written consent in accordance with the Declaration of Helsinki. The study was approved by the research ethics committee of the University.

Table 1: Characteristics of study subjects.

\begin{tabular}{lcc}
\hline & Obese & Non-obese \\
\hline Age (Years) & $15.9 \pm 1.4$ & $15.3 \pm 1.2$ \\
\hline Body mass $(\mathrm{kg})$ & $84.45 \pm 5.6$ & $58.53 \pm 7.1^{*}$ \\
\hline Height $(\mathrm{m})$ & $1.62 \pm 0.06$ & $1.61 \pm 0.09$ \\
\hline Body mass index $(\mathrm{kg} / \mathrm{m} 2)$ & $32.40 \pm 3.7$ & $22.58 \pm 1.9^{*}$ \\
\hline \% body fat & $39.6 \pm 4.8$ & $18.3 \pm 3.1^{*}$ \\
\hline Tanner stage $(\%)$ & & \\
Stage 1 & 0.0 & 0.0 \\
Stage 2 & 0.0 & 0.0 \\
Stage 3 & 3.2 & 2.6 \\
Stage 4 & 8.4 & 7.7 \\
Stage 5 & 88.4 & 89.7 \\
\hline
\end{tabular}

* Significant difference between obese and non obese $\mathrm{p}<0.001$

\subsection{Method}

The study was conducted during the 2009-2010 school year. All subjects participated for an average of 12 weeks to a fitness program. Before the first and after the last training session, subjects were asked to fill in a self-esteem questionnaire by Rosenberg [28] and to keep a Spielberger state anxiety Inventory [29]. Subjects were asked to be alone and away from any other person so that there is no communication during the experiment. Encouragement, criticism or any other form of investment have been banned.

\subsubsection{The self-esteem scale of Rosenberg}

The self-esteem scale of Rosenberg [29], which contains 10 items, is an assessment of global selfesteem that the person may have. To assess self-esteem, just make the total, of marks. So a score between 10 and 40 is obtained.

If you get a score less than 25 , self-esteem is very low. Work in this area appears desirable.

If you get a score between 25 and 31, self-esteem is low. Work in this area would be beneficial.

If you get a score between 31 and 34, self-esteem is average.

If you get a score between 34 and 39, self-esteem is strong. asserted.

If you get a score higher than 39 , self-esteem is very strong and the person tends to be strongly 


\subsubsection{The questionnaire Spielberger state anxiety}

The questionnaire Spielberger state anxiety [30] includes 20 items to assess feelings of apprehension, tension, nervousness and anxiety caused by a specific situation. This questionnaire is an indicator of transient changes of anxiety caused by aversive or therapeutic situations.

To assess anxiety, simply add the marks;

For women the average is 42 .

For men the average is 37.

If the score is above the average, the competitive situation generates significant anxiety. The higher the score the higher the competitive situation is experienced as anxiety.

For men, if the score exceeds 48 , the anxiety interferes with competitive performance.

For women, if the score exceeds 55, the anxiety interferes with athletic performance.

\subsection{Anthropometric evaluation}

All anthropometric measurements were performed once before the first session of the training program and again after the last session. Weight and height were measured among participants in an upright position, wearing light clothing and bare foot. The size of the subjects was measured using a stadiometer, to the nearest centimeter. Subjects were also weighed on scales Seca (alpha model 770), 100 grams. Overweight was defined as a body mass index (BMI [weight/height2] $\geq 25$ ). Obesity was defined from a BMI $\geq 30$ according to international standards recently established [31]. The percentage of body fat was calculated using a measuring device such Harpenden Skinfold Caliper (Harpenden, UK) at four standardized sites (biceps, triceps, subscapula and suprailium). The four measures were then summed and converted to body fat percentage using the Durnin and Womersley table [31].

\subsection{Pubertal assessment}

Pubertal status was measured with a self-assessment questionnaire using gender-specific line drawings of the Tanner puberty stages [32]. Participants were asked to complete this alone and in private at home. All participants reported being either in puberty or completing puberty.

Pubertal stage was evaluated according to the Tanner classification [32] by a trained paediatrician:

- prepubertal children were those in Tanner stage I;

- pubertal children were in Tanner stages II-III;

- and post-pubertal children were in Tanner stages IV-V.

\subsection{Training program}

The physical training program consists of running, walking, physical strengthening and stretching muscles for 2 sessions a week. Each session lasts about 50 minutes. Heart rate was controlled using a Polar heart rate monitor during the training sessions (Polar, Finland).

The training program is divided into three periods:

\section{- Period 1: from week 1 until the end of Week 3:}

We proposed an aerobic endurance program fractionated upon 3 repetitions of 10 minutes. The subject recovers completely after every 10 minutes of racing. Training intensity during each repetition is equal to $50 \%$ of the maximum heart rate of the subject.

$$
\mathrm{HR}_{\max }=191.5-0.007 \mathrm{x} \text { age }^{2}[34]
$$

As the subject is informed about the intensity of work before the start of training, must follow his heart rate on the display of heart rate to keep it in the meantime. At the end of a 10 minutes run, the subject walk until the heart rate returns to its resting value, which marks the beginning of the second repetition. At the end of each session, subjects performed muscular strengthening exercises (abs, dorsal and squats). These exercises consist of 3 sets of 10 repetitions with 30 seconds recovery between repetitions. Each session ends with stretching muscular exercises.

\section{- Period 2: from week 4 until the end of Week 7:}

The training is divided into 2 repetitions of 15 minutes per session at an intensity equivalent to $60 \%$ of the maximum heart rate of the subject. In addition to the race, the subjects performed 3 sets of 20 repetitions (abs, dorsal and squats) with a recovery of 30 seconds between repetitions. The session ends with stretching muscular exercises.

\section{- Period 3: week 8 until the end of week 12:}


$70 \%$ of the maximum heart rate of the subject is the training intensity during this period. At each session, the subject performs two fifteen-minute races separated by a complete recovery. Then, the subjects performed 3 sets of 30 reps (abs, dorsal and squats) with a recovery of 30 seconds between repetitions. The session ends with stretching muscular exercises.

\subsection{Statistical analyses}

All statistical tests were processed using STATISTICA Software (StatSoft, France). All data are expressed as mean \pm SD. Several two-factor variance analyses were applied to measure the effect of independent variables on each dependent variable. When a significant effect is noticed, a post hoc Least Significant Difference (LSD) test was applied to compare data pairs. Statistical significance was set at $\mathrm{p}<0.05$.

\section{Results}

Our physical exercise program allowed us to get significant changes in body composition in obese subjects, but not in control subjects. Thus, the obese lost $1.73 \pm 0.7 \mathrm{~kg}(\mathrm{p}=0.006)$, which corresponds to a decrease of $2 \%$. The fat loss was $2.38 \pm 0.4 \mathrm{~kg}$ ( $\mathrm{p}<0.001$ ), which corresponds to a decrease of $6 \%$.

Regarding self-esteem, analysis of variance with two factors (group x training) showed a significant group effect (obese, non obese) $[\mathrm{F}(1,29)=84.86$, p <0.001], a significant effect training $[\mathrm{F}(1,29)=87.81, \mathrm{p}$ $<0.001]$, and a significant interaction (group $\mathrm{x}$ training) $[\mathrm{F}(1 ; 29)=74.39 ; \mathrm{p}<0.001]$.

Before the training program, the LSD post hoc analysis has shown that obese subjects are characterized by low self-esteem $(\mathrm{p}<0.001)$ compared to non-obese subjects. However, after the training program, there is no significant difference between obese and non-obese at the self-esteem $(p=0103)$. Thus, we did not find a significant improvement in self-esteem $(+0.6 \%, \mathrm{p}>0.05)$ in non-obese subjects after the training program. In contrast, in obese subjects, we noticed an improvement in self-esteem $(+17.9 \%, \mathrm{p}<0.001)$.

Regarding anxiety, ANOVA two-factor (group x training) showed a significant group effect (obese, non obese) $[\mathrm{F}(1,29)=1383.88, \mathrm{p}<0.001]$, a significant effect training $[\mathrm{F}(1,29)=145.28, \mathrm{p}<0.001]$, and a significant interaction (group $\mathrm{x}$ training) $[\mathrm{F}(1,29)=81.40, \mathrm{p}<0.001]$. The LSD post hoc analysis has shown that obese subjects show more anxiety than non-obese subjects before $(\mathrm{p}<0.001)$ and after $(\mathrm{p}<0.001)$ training program. Similarly, there has been a decrease in anxiety in obese subjects $(-16.3 \%, \mathrm{p}<0.001)$ and non-obese $(-$ $3.2 \%, \mathrm{p}<0.001)$ after the training program.

Table 2: Effect of physical training on anthropometric parameters (mean \pm SD).

\begin{tabular}{lcccc}
\hline & \multicolumn{2}{c}{ Obese } & \multicolumn{2}{c}{ Non-obese } \\
\hline Body mass $(\mathrm{kg})$ & Pre & Post & Pre & Post \\
\hline BMI $\left(\mathrm{kg} / \mathrm{m}^{2}\right)$ & $84.45 \pm 5.6$ & $82.72 \pm 5.1^{*}$ & $58.53 \pm 7.1$ & $58.16 \pm 7.3$ \\
\hline \% body fat & $32.40 \pm 3.7$ & $30.26 \pm 3.6^{* *}$ & $22.58 \pm 1.9$ & $22.10 \pm 1.4$ \\
\hline
\end{tabular}

*: Significant difference compared to pre training at $\mathrm{p}<0.01 ; * * \mathrm{p}<0.001$

Table 3: Mean state anxiety and self-esteem of obese and non-obese.

\begin{tabular}{llcccc}
\hline & Groups & Pre & Post & $\Delta(\Delta \%)$ & ANOVA \\
\hline \multirow{2}{*}{ Self- } & Obese & $28.33 \pm 1.72$ & $33.42 \pm 1.24 \#$ & $5.09(17.9 \%)$ & \multirow{2}{*}{$\mathrm{F}_{(1 ; 29)}=74.39 ; \mathrm{p}<0.001$} \\
esteem & Non-obese & $34.05 \pm 1.18^{*}$ & $34.26 \pm 0.87$ & $0.21(0.6 \%)$ & \\
\hline \multirow{2}{*}{ Anxiety } & Obese & $51.58 \pm 1.08$ & $43.17 \pm 1.64 \# \#$ & $-8.41(-16.3 \%)$ & \multirow{2}{*}{$\mathrm{F}_{(1 ; 29)}=81.40 ; \mathrm{p}<0.001$} \\
& Non-obese & $36.74 \pm 1.10^{*}$ & $35.53 \pm 1.54 \# *$ & $-1.21(-3.2 \%)$ & \\
\hline
\end{tabular}

\# : Significant difference compared to pre training at \#: $\mathrm{p}<0.05 ; \# \#: \mathrm{p}<0.001$

*: Significant difference compared to obese $\mathrm{p}<0.001$

\section{Discussion}

The aim of this study was to investigate the effect of a 12 weeks training program on anxiety and selfesteem among adolescent obese and non-obese subjects.

Our results showed that training program resulted in a significant reduction in body mass and body fat percentage. In addition, our results showed the beneficial effects of training program on reducing anxiety and improving self-esteem in obese adolescents. Our results are consistent with those of previous studies [34]; [35]; [36]; [37]. Those latter indicated the existence of a proportionally inverse relationship between body weight and self-esteem among adolescents. In addition, our results confirm the view that overweight precedes the manifestation of low self-esteem, rather than the reverse [38]. So we can predict that obesity is a predictor of 
low self-esteem [39]. However, low self-esteem can also lead to academic underachievement, increased susceptibility to drug addiction and alcoholism [40]; [41] and, in some cases, an auto-destructive behavior [42]; [41]. Other studies showed that low self-esteem is associated with subsequent mental health problems like anxiety [43]; [44].

However, after a three months training, there was a significant improvement in psychic abilities compared to the control group (improved self-esteem and anxiety reduction). Thus, our results are consistent with studies showing that regular exercise for obese or overweight subjects are positively associated with improved physical health and self-esteem [45]; [46]. The weight loss phase is a time perceived by the person as particularly beneficial as he/she feels very quickly a decrease in anxiety, feelings of depression and dissatisfaction with the body, and an increase in self-esteem [47]; [48]; [49]. Prospective studies showed that obese adolescents are at risk of major anxiety and the depression disorders later in life [50]. When obesity becomes chronic, the inability to control weight gain over a long period may predispose children affected with depression [51]; [52]. The more the child is overweight, the more likely he is suffer from anxiety disorder and other mental health disorders [53]. In addition, anxiety during childhood is associated with a higher body mass index (BMI) during adolescence and adulthood [53]; [54]. Ng \& Jeffery [55] have shown that anxiety induces the intake with a strong preference for foods rich in sugar and fat. This weight gain then leads to the deterioration in the quality of life of subjects and a poor self-esteem, resulting a new weight gain [56]; [36]. Kaplan \& Kaplan [57] showed that weight gain and development of obesity in humans can be attributed to quality of life factors, especially anxiety and stress. However, physical inactivity is a major cause of obesity in western countries. Similarly, over-eating is the most important, risk factor. Thus, physical activity should be a part of any program to reduce or merely maintain weight only.

\section{Conclusion}

Our study seems to highlight the importance of physical activity for obese adolescents in their identity development and emotional control.

Obese adolescents typically spend less time doing moderate activities than normal weight children [59], due to fatigue stress, a decrease of cardiorespiratory endurance, a lack of self-esteem, social isolation or orthopedic problems. Many authors [59]; [60] agree on the need to involve in the management of obese children dietary measures, physical activity and psychological assistance. The best strategy is based both on reducing sedentary behaviors and increased physical activity associated with energy restriction. So, physical and sporting activity should be an integral part of the overweight management. They represent a beneficial factor on health, on both the physiological and psychosocial sides [61]; [62]; [63]. Saris et al. [64] have suggested that the practice of moderate intensity activity from 60-90 minutes per day (approximately $2500 \mathrm{kcal} / \mathrm{week}$ ) combined with a balanced diet is necessary for weight control, especially after weight loss in the obese but also to prevent the transition from an overweight status to an obese status. Management of obesity must begin with the consideration of overweight. We should not expect this trend to spread and that the BMI exceeds the recommended limits/levels. Physical activity should be adapted to the capabilities of the child or adolescent to avoid discouragement and abandonment. The adapted physical activity programs for obese children and adolescents enable them to improve their conditions and physical abilities, as well as to allow them to integrate within a group of similar individuals where they do not need to hide from view of each other.

\section{Acknowledgments}

The authors thank all subjects for their voluntary participation in this study. The authors wish to express their sincere gratitude to all the participants for their cooperation. This study did not involve any financial external support.

\section{References}

[1] Rolland-Cachera MF, Spyckerelle Y, Deschamps JP, 1991. Evolution of pediatric obesity in France. Int J Obesity; 156 (Suppl 1): 5.

[2] Kuczmarski RJ, Flega KM, Campbell SM, Johnson CL, 1994. Increasing prevalence of overweight among US adults. The National Health and Nutrition Examination Surveys, 1960 to 1991. JAMA ; 272: 205-11.

[3] Ziegler O and Derby O, 1998. Épidémiologie des obésités de l'adulte. Encycl Méd Chir (Elsevier, Paris), Endocrinologie-Nutrition, 10-506-B-20, 7p.

[4] Singh AS, Mulder C, Twisk JWR, van Mechelen W, Chinapaw MJM. 2008. Tracking of childhood overweight into adulthood: a systematic review of the literature. Obes Rev 9:474-488.

[5] Ruiz JR, Castro-Pinero J, Artero EG, 2009. Predictive validity of health-related fitness in youth: a systematic review. Br J Sports Med; 43(12):909-23.

[6] Dietz WH. 1994. Critical periods in childhood for the development of obesity. Am J Clin Nutr 59:955-959.

[7] Jasik CB, Lustig RH. 2008. Adolescent obesity and puberty: the "perfect storm". Ann N Y Acad Sci 1135:265-279.

[8] Nader PR, Bradley RH, Hout DS, McRitchie SL, O’Brien M. 2008. Moderate-to-vigorous physical activity from ages 9 to 15 years. JAMA 300:295-305.

[9] Alberga AS, Sigal RJ, Goldfield G, Prud'homme D, Kenny. 2012. Overweight and obese teenagers: why is adolescence a critical period?, Pediatr Obes doi: 10.1111/j.2047-6310.2011.00046.x. 
[10] Hills AP, Andersen LB, Byrne NM. 2011. Physical activity and obesity in children. Br J Sports Med 45:866-870.

[11] Waters E, de Silva-Sanigorski A, Hall BJ, Brown T, Campbell KJ, Gao Y, Armstrong R, Prosser L, Summerbell CD. 2010. Interventions for preventing obesity in children. Cochrane Database Syst Rev 12, CD001871.

[12] Jiménez-Pavón D, Castillo MJ, Moreno LA, Kafatos A, Manios Y, Kondaki K, Béghin L, Zaccaria M, de Henauw S, Widhalm K, Molnár D, SjöStröm M, González-Gross M, Ruiz JR, HELENA Study Group 2011. Fitness and fatness are independently associated with markers of insulin resistance in European adolescents; the HELENA study. Int J Pediatr Obes 6:253-260.

[13] Nassif H, El Helou N \& Toussaint JF. 2009. Activités physiques ou sportives : quels bénéfices ? Quels risques ? Actualité Dossier Santé Publique ; 67:18-9.

[14] Malina, R.M. (2007) Body composition in athletes: assessment and estimated fatness. Clinics in Sports Medicine 26, 37-68.

[15] Goodman. E, Whitaker.R (2002). A prospective study of the role of depression in the development and persistence of adolescent obesity. Pediatrics, 109, pp. 497-504.

[16] Deforche B, De Bourdeaudhuij I, Tanghe A, Debode P, Hills AP, Bouckaert J, 2005. Role of physical activity and eating behaviour in weight control after treatment in severely obese children and adolescents. Acta Paediatr; 94:464-70.

[17] OMS; World Health Organization. BMI classification 2004. <http://www.who.int/bmi/index.jspintroPage=intro_3.html>

[18] Safont, C. (1992). Orientation de soi à l'adolescence : ses relations avec l'estime de soi et la compétence sociale. Thèse de Doctorat Nouveau Régime de l'Université de Toulouse II, juin.

[19] Lacoste, S. (2003) L'estime de soi et les stratégies de coping dans la professionnalisation du jeune footballeur, Thèse de Doctorat Nouveau Régime sous la direction de P. Tap, Toulouse Le Mirail.

[20] Puhl, R. M., \& Latner, J. D. (2007). Stigma, obesity, and the health of the nation's children. Psychological Bulletin, 133(4), 557580 .

[21] Stunkard AJ, Wadden TA, 1992. Psychological aspects of severe obesity. Am. J. Clin. Nutr., 1992, 55, 524S-32S

[22] Passer, M. W., (1983). Fear of failure, fear of evaluation, perceived competence and self-esteem in competitive trait-anxious children. Journal of Sport Psychology, 5, 172-188.

[23] Brustad, R. J., \& Weiss, M. R. (1987). Competence perceptions and sources of worry in high, medicum, and low competitive traitanxious young athletes. Journal of Sport Psychology, 9, 97-105.

[24] Brustad, R. J. (1988). Affective outcomes in competitive youth sport: The influence of intrapersonal and socialization factors. Journal of Sport and Exercise Psychology, 10, 307-321.

[25] Cortes, B.P., Demoulin, S., Rodriguez, R.T., Rodriguez, A.P. et Leyens, J.-P. 2005. Infrahumanization or Familiarity? Attribution of Uniquely Human Emotions to the Self, the Ingroup, and the Outgroup. Personality and Social Psychology Bulletin, 31 (2), 243253.

[26] Buddeberg-Fischer, 2004. Impact of psychosocial stress and symptoms on indication for bariatric surgery and outcome in morbidly obese patients. Obes Surg; 14: 361-9.

[27] Buddeberg-Fischer B, Klaghofer R, Reed V, 1999. Associations between body weight, psychiatric disorders and body image in female adolescents. Psychother. Psychosom; 68:325-332.

[28] Rosenberg, M. (1990). The self-concept: Social product and social force. Social Psychology: Sociological Perspectives, 593-624.

[29] Spielberger CD, 1983. Manual for the State-Trait Anxiety Inventory. Consulting Psychologist Press Inc., Palo Alto, California. New York: Oxford University Press.

[30] Cole TJ, Bellizi MC, Flegal KM, Dietz WH, 2000. Establishing a standard definition for child overweight and obesity worldwide. International survey. BMJ; 320: 1240-3.

[31] Durnin, J.V.G.A., \& Womersley, J. (1974). Body fat assessed from total density and its estimation from skinfold thickness: Measurements on 481 men and women aged from 16 to 72 years.

[32] Taylor SJ, Whincup PH, Hindmarsh PC, Lampe F, Odoki K, Cook DG. 2001. Performance of a new pubertal self-assessment questionnaire: a preliminary study. Paediatr Perinat Epidemiol 15:88-94.

[33] Gellish L, Goslin R, Olson E, McDonald A, Russi D, Moudgil K. 2007. Longitudinal modeling of the relationship between age and maximal heart rate. Medicine and science in sports and exercise, vol. 39, no 5, p. 822-829.

[34] Faith M.S, Berman N, Heo M Pietrobelli, A Gallagher, D Epstein, L Eiden \& M.T - Allison, D.B. 2001. Effects of contingent television on physical activity and television viewing in obese children. Pediatrics, 107, 1043-1048.

[35] French S.A., Story M. \& Perry C.L., 1995. Self-esteem and obesity in children and adolescents: a literature review. Obesity Research, 3(5), p. 479-490.

[36] Wardle J. \& Cooke L., 2005. The impact of obesity on psychological well-being. Best Practice and Research Clinical Endocrinology and Metabolism, 19(3), p. 421-440.

[37] Wang F.F. and Veugelers P.J., 2008. Selfesteem and cognitive development in the era of the childhood obesity epidemic. Obesity Reviews, 9, p. 615-623.

[38] Hesketh K., Wake M. and Waters E., 2004. Body mass index and parent-reported self-esteem in elementary school children: evidence for a causal relationship. International Journal of Obesity and Related Metabolic Disorders, 28(10), p. 1233-1237.

[39] Wang Y, Chen HJ, Shaikh S, Mathur P (2009). Is obesity becoming a public health problem in India? Examine the shift from underto overnutrition problems over time. Obes Rev 10:456-74.

[40] Gerrard M., Gibbons F.X., Reis-Bergan M. and Russell D.W., 2000. Selfesteem, self-serving cognitions, and health risk behavior. Journal of Personality, 68(6), p. 1177-1201.

[41] Wild L.G., Flisher A.F., Bhana A. and Lombard C., 2004. Substance abuse, suicidality, and self-esteem in South African adolescents. Journal of Drug Education, 34(1), p. 1-17.

[42] McGee. R, Williams. S and Nada-Raja S, 2001. Low self-esteem and hopelessness in childhood and suicidal ideation in early adulthood. Journal of Abnormal Child Psychology, 29(4), p. 281-291.

[43] Paradise A.W. and Kernis M.H, 2002. Self-esteem and psychological well-being: implications of fragile self-esteem. Journal of Social and Clinical Psychology, 21, p. 345-361.

[44] Palosaari U., Aro H. and Laippala P., 1996. Parental divorce and depression in young adulthood: adolescents' closeness to parents and self-esteem as mediating factor », Acta Psychiatrica Scandinavica, 93(1), p. 20-26.

[45] Tremblay M.S., Inman J.W. \& Willms J.D., 2000. The relationship between physical activity, self-esteem and academic achievement in 12-year-old children. Pediatric Exercise Science, 12, p. 312-323.

[46] Spence J.C., McGannon K. \& Poon P., 2005. The effects of exercise and physical activity on self-concept and self-esteem: A metaanalysis. Journal of Sport and Exercise Psychology, 27, p. 311-334.

[47] Cooper, Z., \& Fairburn, C. G. (2001). A new cognitive behavioural approach to the treatment of obesity. Behaviour Research and Therapy, 39, 499-511. 
[48] Foster, G. D., \& Wadden, T. A. (1994). The psychology of obesity, weight loss, and weight regain: Research and clinical findings. Dans G. L. Blackburn et B. S. Kanders (Éds.). Obesity: Pathophysiology, psychology and treatment (p. 140-166). New York : Chapman \& Hall.

[49] O’Neil, P. M., \& Jarrell, M. P. (1992). Psychological aspects of obesity and dieting. Dans T. A. Wadden and T. B. VanItallie (Éds.), Treatment of the seriously obese patient (p. 252-270). New York: Guilford.

[50] Anderson SE, Cohen P, Naumova EN, Jacques PF, Must A 2007. Adolescent obesity and risk for subsequent major depressive disorder and anxiety disorder: Prospective evidence. Psychosom Med; 69(8):740-7.

[51] Erermis S, Cetin N, Tamar M, Bukusoglu N, Akdeniz F, Goksen D, 2004. Is obesity a risk factor for psychopathology among adolescents. Pediatr Int; 46(3):296-301.

[52] Mustillo S, Worthman C, Erkanli A, Keeler G, Angold A, Costello EJ, 2003. Obesity and psychiatric disorder: Developmental trajectories. Pediatrics; 111(4 Pt 1):851-9.

[53] Pine DS, Goldstein RB, Wolk S, Weisman MM, 2001. The association between childhood depression and adulthood body mass index. Pediatrics; 107(5):1049-56.

[54] Goodman E and Whitaker RC, 2002. A prospective study of the role of depression in the development and persistence of adolescent obesity. Pediatrics; 110(3):497-504.

[55] Ng DM and Jeffery RW, 2003. Relationships between perceived stress and health behaviors in a sample of working adults. Health Psychol; 22:638-42.

[56] Torres, S.J., Nowson, C.A., 2007. Relationship between stress, eating behavior, and obesity. Nutrition 23, 887-894.

[57] Kaplan, H. L, \& Kaplan, H. S. (1957). The psychosomatic concept of obesity. Journal of Nervous and Mental Diseases, 125(2), 181-201.

[58] Trost S.G., Kerr L.M., Ward D.S., Pate R.R. (2001): Physical activity and determinants of physical activity in obese and non-obese children. Int. J. Obes. Relat. Metab. Disord. 25: 822-829.

[59] Vannereau D, Richard JL, Parer-Richard C. In : Herisson C, Prefaut C, Kotzki N, 1995. Activités physiques et obésité. Le réentraînement à l'effort. Paris : Masson; p. 181-95.

[60] Maffeis C, Tato L, 1998. Quel rôle jouent l'activité physique et la sédentarité dans le développement et le maintien de l'excès de poids chez l'enfant. Arch Pédiatr; 5: 1191-6.

[61] Strong WB, Malina RM, Blimkie CJ, 2005. Evidence based physical activity for school-age youth. J Pediatr; 146:732-7.

[62] Watts K, Jones TW, Davis EA, Green D, 2005. Exercise training in obese children and adolescents: current concepts. Sports Med; 35:375-92.

[63] Atlantis E, Barnes EH, Singh MA 2006. Efficacy of exercise for treating overweight in children and adolescents: a systematic review. Int J Obes (Lond); 30:1027-40.

[64] Saris WH, Blair SN, van Baak MA, Eaton SB, Davies PS, Di Pietro L, 2003. How much physical activity is enough to prevent unhealthy weight gain? Outcome of the IASO 1st Stock Conference and consensus statement. Obes Rev; 4:101-14. 